DOI: http://dx.doi.org/10.1590/1981-7746-sol00183

\title{
EVOLUÇÃO, DISTRIBUIÇÃO E EXPANSÃO DOS CURSOS DE MEDICINA NO BRASIL (1808-2018)
}

\author{
EVOLUTION, DISTRIBUTION AND EXPANSION \\ OF MEDICINE COURSES IN BRAZIL (1808-2018)
}

\author{
Bruno Luciano Carneiro Alves de Oliveira (D) (https://orcid.org/0000-0001-8053-7972) ${ }^{1}$, Sara Fiterman Lima \\ (D) (https://orcid.org/0000-0003-0015-3413) ${ }^{1}$, Marina Uchoa Lopes Pereira ID (https://orcid.org/0000-0001-7999-9096) ${ }^{1}$, \\ Gerson Alves Pereira Júnior (iD) (https://orcid.org/0000-0003-3920-3000)²
}

\author{
${ }^{1}$ Universidade Federal do Maranhão, Faculdade de Medicina Campus Pinheiro, São Luís, Maranhão, \\ Brasil.<brunodeoliveirama@gmail.com> \\ ${ }^{2}$ Universidade de São Paulo, Faculdade de Medicina Campus Bauru, Bauru, São Paulo, Brasil.
}

\begin{abstract}
Resumo O estudo identificou o padrão de evolução, distribuição e expansão dos cursos de medicina no Brasil e descreveu os processos governamentais relacionados à ampliação da oferta de vagas. Trata-se de estudo descritivo, baseado em dados disponíveis no sistema do Ministério da Educação sobre escolas médicas. Com as informações sobre os cursos, desde os primeiros implantados, estabelecem-se seis períodos de governo para análise: de 1808 a 1963 (monarquia e governos republicanos iniciais), de 1964 a 1988 (governos militares - José Sarney), de 1989 a 1994 (Fernando Collor - Itamar Franco), de 1995 a 2002 (Fernando Henrique Cardoso), de 2003 a 2010 (Lula) e 2011 a 2018 (Dilma Rousseff - Michel Temer). Observou-se relevante expansão de escolas a partir dos governos militares, com pico em 2014 (Dilma Rousseff), frente à implementação do Programa Mais Médicos. Ao longo dos períodos analisados, o ensino médico tornou-se progressivamente privatizado e parcialmente deslocado para as Regiões Norte, Nordeste e Centro-Oeste e para cidades de médio e pequeno portes populacionais no interior dos estados. Os resultados apontam que a combinação de gestão governamental das políticas de saúde e educação e de desenvolvimento socioeconômico influenciaram a expansão dos cursos de medicina e as marcadas diferenças intra e interregionais. Palavras-chave educação médica; políticas de saúde; distribuição de médicos; expansão; interiorização de escolas médicas.
\end{abstract}

Abstract The study identified the pattern of evolution, distribution and expansion of the undergraduate medicine courses in Brazil and described the governmental processes related to the increase in the capacity of the courses. It is a descriptive study based on data available in the system of the Brazilian Ministry of Education about medical schools. With information about the courses dating back to the first that were implemented in the country, we could establish six periods of government for the analysis: from 1808 to 1963 (from the Monarchy to the first republican governments); from 1964 to 1988 (from the military dictatorship to the government of José Sarney); From 1989 to 1994 (Fernando Collor - Itamar Franco); from 1995 to 2002 (Fernando Henrique Cardoso); from 2003 to 2010 (Lula); and from 2011 to 2018 (Dilma Rousseff Michel Temer). We observed a significant expansion of the schools starting with the military dictatorship and peaking in 2014 (Dilma Rousseff), and the implementation of the More Doctors Program (Programa Mais Médicos, in Portuguese). Throughout the analyzed periods, the teaching of Medicine became ever more privatized, and was partially shifted to the Northern, Northeastern and Midwestern regions of Brazil, and to medium-sized and small municipalities in the countryside of the states. The results indicate that the combination of the management by the government of the health, education and socioeconomic development policies had an influence on the expansion of the Medicine undergraduate courses and the marked intra- and interregional differences.

Keywords medical education; health policies; distribution of physicians; expansion; medical school shift to the countryside. 


\section{Introdução}

O ensino médico no Brasil, desde a sua fundação até os dias atuais, vem sendo fortemente influenciado por decisões e conjunturas políticas, regimes de governo, modelos econômicos, propostas de intervenção social e de gestão das diferentes políticas públicas. Esses múltiplos elementos marcaram as características de evolução, distribuição e expansão desses cursos no país (Amaral, 2016).

As primeiras escolas de ensino médico no Brasil foram criadas em 1808 e até a primeira década do século XX havia apenas três dessas instituições. A década de sessenta, com a criação de 35 escolas, acabou sendo marcada por um processo intenso de expansão. Ao longo dos anos seguintes, essa ampliação permaneceu e, ao final do século passado, alcançou 113 escolas implantadas (Amaral, 2016; Lampert, 2008). Neste século, em período de menos de 20 anos, a expansão intensificou-se ainda mais e quase triplicou. No final de 2010, o número de cursos ativos chegou a 179 e alcançou a marca de 323 em 2018 (Brasil, 2018).

O início dessa dinâmica de expansão ocorreu a partir das décadas de 1960/1970. Nesse período, iniciou-se para todas as profissões o próprio processo de expansão do ensino superior no país. Essa fase foi marcada pela multiplicação de escolas de graduação e do número de vagas. Por um lado, esse processo permitiu ascensão social nas camadas médias da sociedade a diferentes graduações. Por outro, o contexto de desenvolvimento econômico do país exerceu forte pressão para o desenvolvimento da educação no ensino superior como importante dimensão da economia de mercado (Amaral, 2016; Haddad et al., 2010).

$\mathrm{Na}$ área da saúde, a formação foi impulsionada por estudos e debates que, à época, estabeleciam como referência a relação entre tamanho populacional e o número de médicos, o estímulo à formação de enfermeiros e à qualificação de pessoal de níveis médio e elementar (Haddad et al., 2010). Também influenciaram, nesse processo, o modo de organização do setor saúde, a industrialização e urbanização crescente. Com isso, a política expansionista teve relação direta com o desenvolvimento econômico, tecnológico, político e social do país.

Com a Constituição de 1988, consolidou-se a interface saúde e educação, que acabou conferindo ao ensino médico a condição de fator estratégico para a formação e ordenação dos recursos humanos no processo de implantação do novo sistema de saúde brasileiro - o Sistema Único de Saúde (SUS) (Amaral, 2016).

A Constituição de 1988 atribuiu ao SUS a missão de ordenar a formação de recursos humanos para a área da saúde (Brasil, 1988). Assim, o Ministério da Saúde, desde 2003, por meio do Departamento de Gestão da Educação na Saúde, da Secretaria de Gestão do Trabalho e da Educação na Saúde, passou 
a desenvolver e apoiar ações no campo da formação e desenvolvimento dos profissionais de saúde (Haddad et al., 2010; Oliveira, Sanches e Santos, 2016).

Registram-se, ao longo dos anos, várias iniciativas para atração e fixação de profissionais de saúde em regiões remotas, como, por exemplo: o Programa de Interiorização das Ações de Saúde e Saneamento (1976), o Programa de Interiorização do Sistema Único de Saúde (1993), o Programa de Interiorização do Trabalho em Saúde (2001), o Programa de Valorização dos Profissionais da Atenção Básica (2011) e, mais recentemente, o Programa Mais Médicos (PMM - 2013) (Brasil, 2012; Oliveira et al., 2015).

O provimento inadequado ou excessivo de profissionais de saúde consiste em problema que afeta o Brasil assim como a muitos outros países, principalmente em relação à concentração de médicos nos grandes centros urbanos e sua baixa presença em áreas mais remotas (Santos, Costa e Girardi, 2015).

O tema recursos humanos ocupou a agenda da política do país como ponto fundamental para a implementação dos sistemas nacionais de saúde. Entretanto, considerando a desarticulação acumulada na implantação de políticas sociais envolvendo os setores educacional e de prestação de serviços, estes sistemas passaram a enfrentar diversos desafios relativos a aspectos quantitativos (distribuição e fixação de médicos) e qualitativos (qualidade da formação médica) (Haddad et al., 2010; Mello e Demarzo, 2015).

Nessa perspectiva, mais recentemente a lei n. 12.871, de 22/10/2013, introduziu no cenário nacional o PMM como parte de uma série de medidas para combater as desigualdades regionais na área da saúde. Para a consecução dos seus objetivos, o programa orientou expansão da oferta de cursos de graduação em medicina, contribuindo para um processo de expansão das escolas médicas que já vinha sendo implementado há muitos anos (Brasil, 2013; Facchini et al., 2016).

Portanto, considerando a relevância das escolas médicas para a educação, desenvolvimento social e assistência à saúde no país, este estudo descreveu o padrão de evolução, distribuição e expansão dessas escolas no contexto nacional, debatendo os processos governamentais relacionados à ampliação da oferta de vagas no país e apresentando questões advindas do contexto atual.

\section{Os dados sobre o ensino médico no Brasil}

Trata-se de estudo descritivo baseado em dados agregados secundários sobre as escolas de ensino médico no Brasil. Tais dados estão disponíveis no sistema eletrônico do Ministério da Educação do Brasil (Cadastro e-Mec de Instituições e Cursos de Educação Superior) (Brasil, 2018).

$\mathrm{O}$ e-MEC é a base de dados oficial e única de informações relativas às instituições de educação superior e cursos de graduação registrados no Sistema Federal de Controle do Ensino de Graduação (Brasil, 2018). Dessa base de da- 
dos, foram coletadas as informações disponíveis sobre as seguintes variáveis a respeito dos cursos de ensino médico: início do funcionamento do curso; município de localização do curso; tipo de instituição (pública ou privada); administração (federal, estadual e municipal); número de vagas ofertadas; localização do curso dentro do estado; porte populacional das cidades com curso de ensino médico (pequeno porte: $<50.000$ habitantes, médio porte: 50.000 a 100.000 habitantes e grande porte: $>100.000$ habitantes); macrorregião do país (norte, nordeste, centro-oeste, sudeste e sul) e Unidades Federativas (UF-estados).

Foram coletadas informações referentes a 323 escolas médicas, com datas de autorização de funcionamento de 1808 até agosto de 2018. Assim, considerando a data de início das atividades de cada uma delas, foram estabelecidos os períodos de governo brasileiros em que esses cursos foram autorizados e estratificados em seis períodos: $1^{\circ}$ - de 1808 até 1963 (considerando a monarquia e os governos iniciais até o período da ditadura que marca o início da expansão); $2^{\circ}$ - de 1964 a 1988 (governos militares e Sarney, considerando estes como não eleitos pelo povo); $3^{\circ}$ - de 1989 a 1994 (governos dos presidentes Collor e Itamar que, juntos, realizaram um único mandato); $4^{\circ}$ - de 1995 a 2002 (governo do presidente Fernando Henrique Cardoso); 5 - de 2003 a 2010 (governo do presidente Lula) e $6^{\circ}$ - de 2011 a 2018 (governos de Dilma Rousseff e Michel Temer que, juntos, integralizam dois mandatos).

Para esses períodos de governos, realizou-se a comparação da distribuição de cursos e vagas de medicina segundo as variáveis selecionadas e descritas acima, apresentando-se as frequências absolutas e relativas dessa distribuição. Foram calculadas, também, as razões do número de vagas criadas nos cursos: privadas/públicas, privadas/total e públicas/total. Para se verificar diferenças estatisticamente significantes $(\alpha=5 \%)$ na distribuição das variáveis de interesse segundo os seis períodos de governos brasileiros em estudo, foram realizados testes de qui-quadrado de Pearson ou teste de exato de Fisher. Todas as análises foram realizadas no software SPSS, versão 23.0 (SPSS Inc., Chicago, Estados Unidos) ${ }^{\circledR}$.

\section{O mapeamento das escolas médicas no Brasil}

No período do estudo, compreendido entre 1808 e agosto de 2018, foram autorizadas ao funcionamento 327 escolas médicas no Brasil. Atualmente, quatro desses cursos encontram-se extintos pelo Ministério da Educação, a saber: um criado em 1965, um no governo FHC e dois durante o governo Lula. As 323 escolas médicas ativas ofertam um total de 32.626 vagas de graduação.

Observaram-se três importantes períodos relacionados ao aumento do número de escolas de ensino médico no país. O primeiro entre 1962 e 1972, o segundo entre 1994 e 2008 e o último entre 2012 e 2018. Nos biênios 2014 
- $2015(\mathrm{n}=51 ; 15,8 \%)$ e $2017-2018(\mathrm{n}=45 ; 14 \%)$, foram criados o maior número dessas escolas no país (Figura 1).

Figura 1.

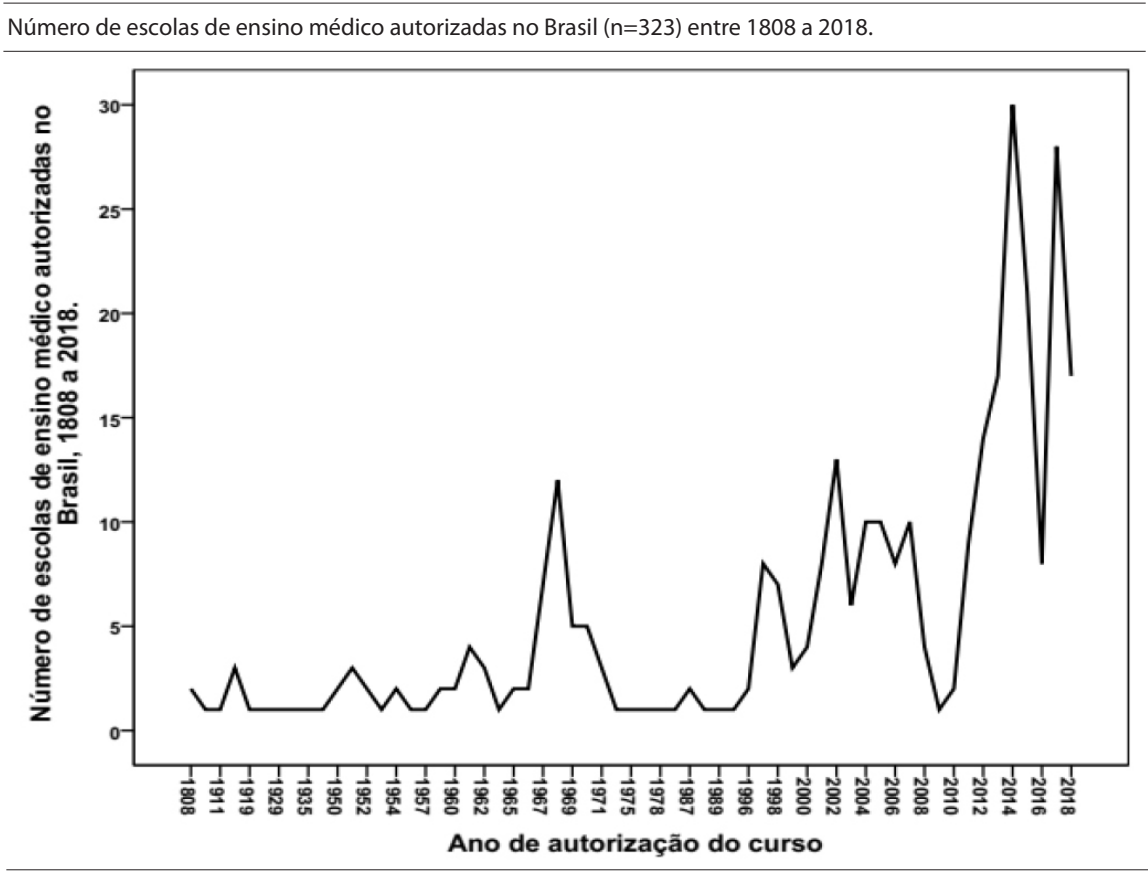

Fonte: Brasil, 2018

Nota: Foram excluídas quatro escolas já extintas no país.

Na Tabela 1, observou-se que a maioria das escolas $(58,5 \%)$ e das vagas de graduação em medicina $(65,8 \%)$ estava sob gestão privada. Entre as instituições de ensino público ( $\mathrm{n}=137), 59,1$ \% eram da administração federal. A maioria das escolas estava localizada nas capitais e regiões metropolitanas (RMs) das Unidades Federativas (UFs) (50,7\%) e um percentual menor no interior dessas UFs (49\%). Cidades de grande porte populacional abrigavam $82 \%$ das escolas. A Região Sudeste abrigava a maioria das escolas $(41,8 \%)$, enquanto Norte $(6,8 \%)$ e Centro-Oeste $(10,5 \%)$, a menor parte.

Ao se comparar a distribuição de cursos de ensino médico segundo os períodos de governos, identificaram-se diferenças estatisticamente significantes para todas as variáveis observadas (Tabela 1). Ao longo dos governos, constatou-se que o ensino médico no país era predominantemente público até 1963, mas houve crescente privatização nessa área ao longo dos governos estudados. De todas as escolas públicas, 22,6\% existiam até 1963, e esse percentual foi sendo reduzido até voltar a crescer e representar $43,1 \%$ nos governos Dilma - Temer. No que se refere ao total de escolas privadas, o incremento começou a ocorrer nos governos militares-Sarney (14,5\%), FHC 
$(15,1 \%)$ e Lula (21\%) e atingiu seu pico nos governos Dilma-Temer, os quais mantiveram o crescimento da proporção de escolas privadas $(45,7 \%)$.

Entre as escolas de ensino médico sob a administração pública $(\mathrm{n}=137)$, as federais tiveram maior proporção nos governos militares-Sarney $(21,6 \%)$, FHC (27\%) e Dilma-Temer (29,7\%) e representam 59,1\% das escolas públicas atuais. Já a criação de escolas estaduais $(42 \%)$ e municipais $(73,7 \%)$ foi mais forte nos governos Dilma-Temer. O número de vagas nas escolas médicas também tem sido ofertado predominantemente por instituições privadas de ensino em todos os governos desde 1963. Esse processo aumentou, continuamente, o percentual de vagas privadas. Passou de 3,2\% até 1962 para 14,5\% nos governos militares-Sarney, 15,1\% nos governos FHC, $21 \%$ nos governos Lula até atingir 45,7\% nos governos Dilma-Temer. Atualmente, essas vagas privadas corresponderem a $65,8 \%$ de todas as vagas do país (Tabela 1 ).

Houve importante processo de interiorização do ensino médico no Brasil com redução da proporção das escolas na capital e aumento daquelas localizadas na RM (excluído capital), e no interior das UFs. A começar dos governos militares-Sarney, reduziu-se a proporção de escolas médicas nas capitais, representando 22,4\% nos governos FHC e 19,4\% nos governos Dilma-Temer. Estes últimos governos criaram 49,3\% das atuais escolas nas RMs, 58,2\% das escolas no interior das UFs em todo o período de estudo. Em relação ao tipo de cidade em que essas escolas foram implantadas, a maioria ocorreu nas cidades de grande porte populacional em todos os períodos dos governos. Das escolas implantadas nessas cidades, cada um dos governos foi responsável pela criação de cerca de $15 \%$ delas. 


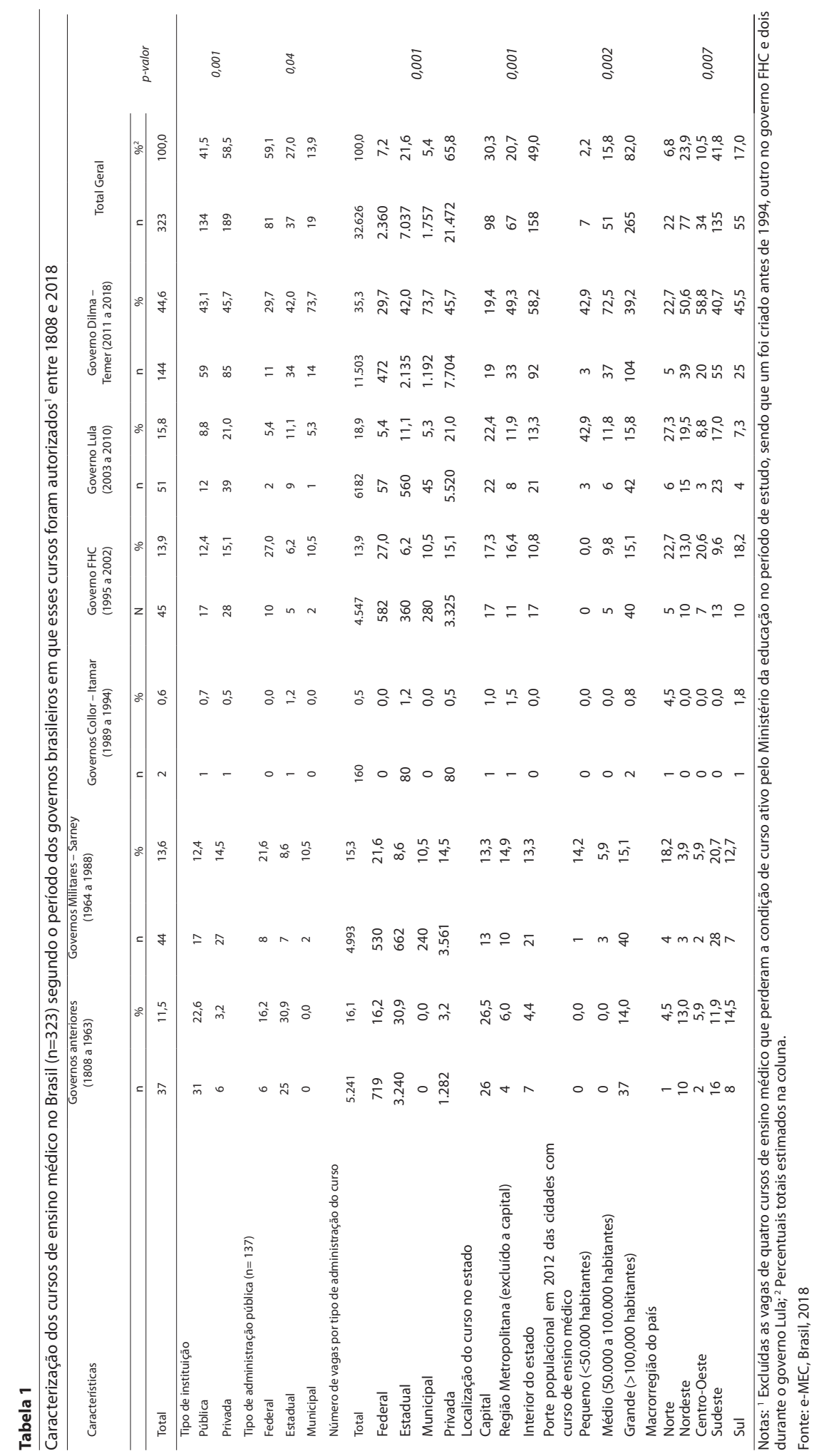


Vale ressaltar que os governos Dilma - Temer criaram a maior parte $(39,2 \%)$ das escolas implantadas nessas cidades. Por outro lado, as de pequeno e médio portes populacionais passaram a ser mais frequentes a partir dos governos Lula.

Entre as escolas das cidades de pequeno porte, $42,9 \%$ foram implantadas nos governos Lula e Dilma - Temer, enquanto $72,5 \%$ das escolas nas cidades de médio porte foram implantadas pelos últimos governos. Entre as regiões do país, a implantação das escolas de medicina tem sido maior no Sudeste e menor na Região Norte. No entanto, ao longo dos governos, progressivamente, aumentou a implantação dessas escolas nas regiões Norte, Nordeste e Centro-Oeste. Na Região Norte, esse percentual aumentou de 4,5\%, até 1963, para 22,7\% no governo FHC, 27,3\% no governo Lula e para $22,7 \%$ nos governos Dilma-Temer. Na Região Nordeste, o percentual aumentou de $13 \%$ nos governos FHC para 19,5\% nos governos Lula e 50,6\% nos governos Dilma-Temer. Já na Região Centro-Oeste, o aumento foi marcadamente importante nos governos Dilma-Temer, que criaram 58,8\% dos cursos dessa região. Apesar desse deslocamento dos cursos para outras regiões, os governos Dilma-Temer ainda foram os que mais implantaram escolas nas Regiões Sul $(45,5 \%)$ e Sudeste $(40,7 \%)$ do país (Tabela 1$)$.

Ao longo dos governos brasileiros, observou-se que a oferta de vagas no ensino médico progressivamente deixou de ser de maioria pública para se tornar de maioria privada. Até 1963, a razão entre o número de vagas privadas/públicas era de 0,32 e passou a ser de 2,5 nos governos militaresSarney; 1,0 nos Governos Collor-Itamar; 2,7 nos governos FHC e de 9,1 nos governos Lula. Nos governos Dilma-Temer, foi reduzida a predominância de vagas privadas, mas essa razão de vagas privadas/públicas ainda foi 2,12 vezes maior (Figura 2).

A frequência absoluta e relativa da evolução da distribuição do número de vagas em escolas de ensino médico entre as regiões, UFs e cidades brasileiras apontou que, até 1994, a maioria das vagas estava concentrada nas escolas localizadas nas Regiões Sul e Sudeste do país, bem como nas capitais da Região Nordeste. 
Figura 2.

Razão do número de vagas privadas públicas total e públicas total em cursos de ensino médico no Brasil segundo os governos em que foram criados esses cursos, entre 1808 a 2018

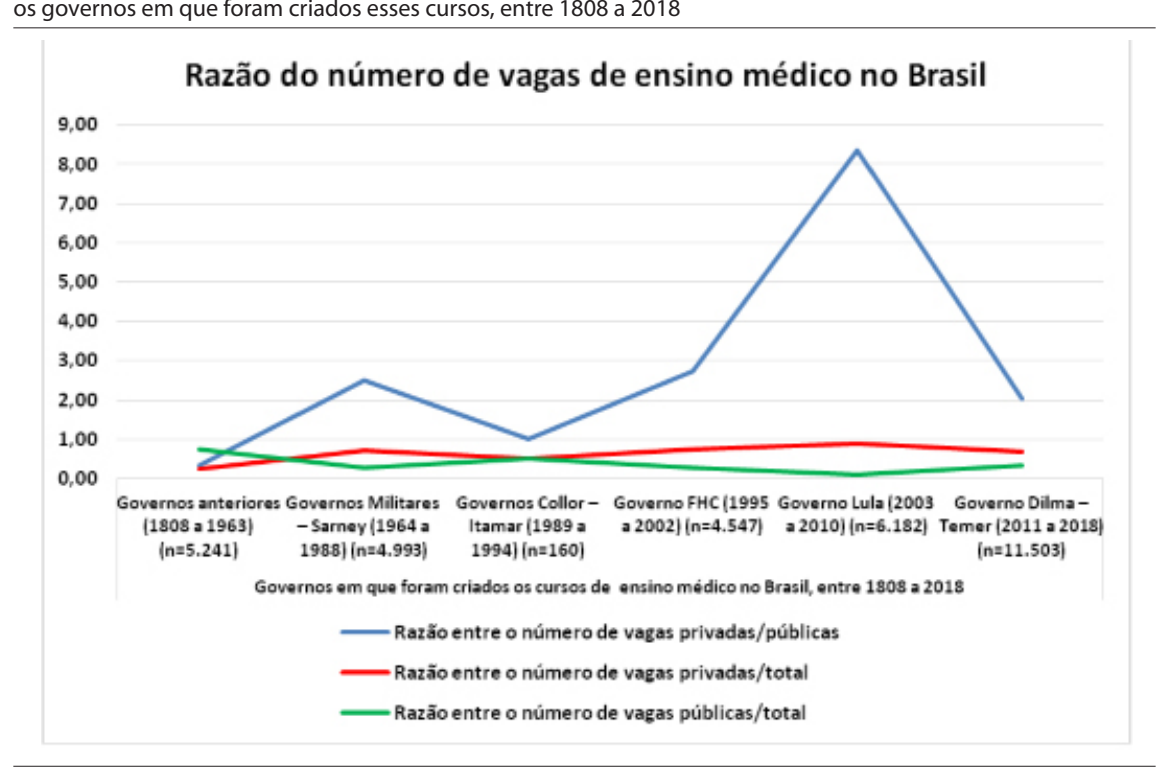

Fonte: e-MEC, Brasil, 2018

No governo FHC, principiou-se a distribuição das vagas para a Região Norte, RM e interior dos estados, sendo, em seguida, intensificado esse processo no governo Lula. Neste governo, iniciou-se o processo de interiorização com implantação de novas vagas, principalmente no interior das UFs do Nordeste-Sudeste-Sul (Tabela 2). O processo de interiorização foi intensificado no governo Dilma-Temer e foi ampliada a implantação de novas vagas nas Regiões Centro-Oeste e Norte do país. Contudo, apesar desses movimentos dos governos entre 1808 e 2018, a Região Sudeste permaneceu com 46,1\% das vagas do país contra $7,5 \%$ na Região Norte. Além disso, em relação ao Brasil, 21,3\% $(n=6.945)$ das vagas de graduação em medicina ficaram concentradas no Estado de São Paulo contra apenas 0,2\% (n=60) no Estado do Amapá. Somente o interior do Estado de São Paulo $(\mathrm{n}=3.474)$ há mais vagas de graduação em medicina do que toda a Região Norte $(n=2.469)$ (Tabela 2). 


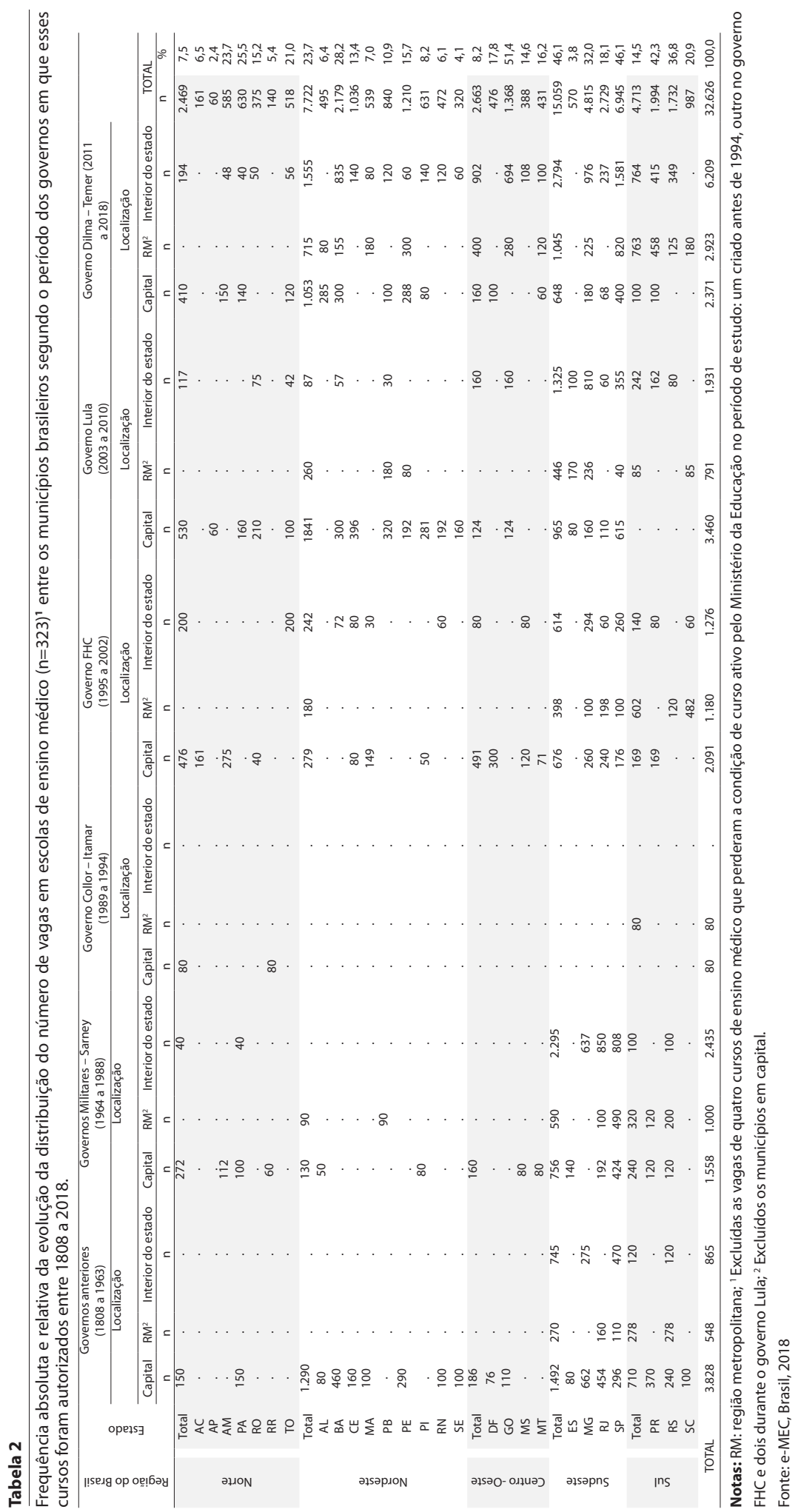


Figura 3

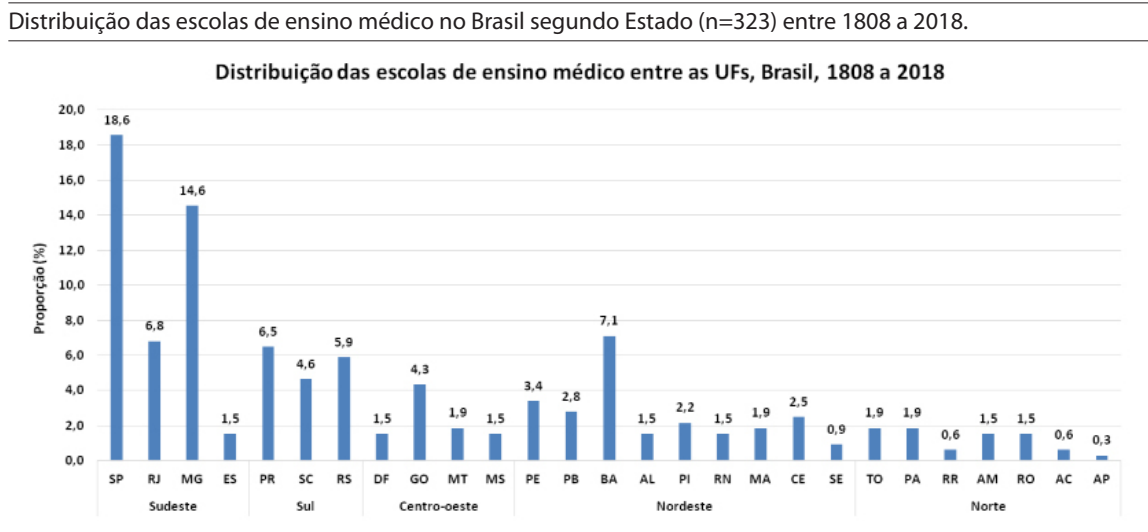

Fonte: e-MEC. Brasil, 2018.

A conjunção dessa distribuição de escolas médicas ao longo dos diferentes governos definiu o desenho atual da proporção dessas escolas entre as UFs e regiões do Brasil, que se caracteriza pela concentração das escolas nas UFs das Regiões Sul-Sudeste do país e baixa proporção em todos os estados da Região Norte. Os Estados de São Paulo (n=60; 18,6\%) e de Minas Gerais $(\mathrm{n}=47 ; 14,6 \%)$ concentraram a maior proporção das escolas do país, contra a menor proporção nos Estados do Amapá (n=1;0,3\%) e Acre (n=2;0,6\%) (Figura 3). Proporcionalmente, o Estado de São Paulo $(18,6 \%$ ) tem mais escolas de medicina que as Regiões Norte $(8,3 \%)$ e Centro-Oeste $(9,2 \%)$ juntas.

\section{A evolução, distribuição e expansão das escolas de medicina no Brasil no período de 1808 a 2018}

Este estudo descreveu a evolução, distribuição e expansão das escolas de medicina no Brasil segundo o período dos governos brasileiros em que esses cursos foram criados. Apontou a influência individual de cada um desses governos na oferta de novas vagas de graduação em medicina no país. Os resultados indicaram que, ao longo dos seis períodos de governo avaliados, o ensino médico tornou-se progressivamente privatizado, com deslocamento das escolas para as Regiões Norte-Nordeste-Centro-Oeste, para cidades no interior das UFs e de médio e grande portes populacionais do país.

Estudos prévios apontam que o ensino médico brasileiro é influenciado pela conjuntura política, pelos regimes de governo, por modelos econômicos e por outros fatores que marcam o desenvolvimento do país. Dessa forma, a configuração dos cursos estaria associada à política de organização acadêmica, à localização geográfica e ao tipo de natureza jurídica dessas instituições (Amaral, 2016). 
Em estudo sobre a oferta de vagas de medicina, Amâncio Filho, Vieira e Garcia (2006) destacam o crescimento acelerado da oferta de cursos e vagas e a crescente privatização do sistema de ensino. Entre as razões possíveis desse quadro, apontam as mudanças provocadas pela Lei de Diretrizes e Bases da Educação Nacional, que favoreceram a criação de cursos e a privatização do ensino, em virtude da maior autonomia concedida às instituições de ensino superior.

Observou-se que, entre 1808 e 2018, a relevante expansão do ensino médico no Brasil ocorreu, principalmente, desde os governos militares-Sarney, intensificaram-se nos governos FHC e Lula, mas atingiram o pico dessa expansão em 2014, com a implementação do PMM no governo Dilma-Temer. Somente entre 2011 e 2018 foram inauguradas mais escolas de ensino médico $(\mathrm{n}=119)$ do que as que foram criadas em 194 anos de história do país (1808 a 2002) $(\mathrm{n}=114)$.

A lei n. 12.871, do Programa Mais Médicos, foi promulgada em 2013 como medida para combater as desigualdades regionais na área da saúde, sendo estruturada em três eixos de ação: investimentos na melhoria da infraestrutura da rede de saúde, principalmente nas unidades básicas de saúde; ampliação e reformas educacionais dos cursos de graduação em medicina e residência médica no país; e provimento emergencial de médicos em áreas vulneráveis. Assim, o programa previa a expansão de escolas, que deveria priorizar regiões de saúde com menor relação de vagas e médicos por habitante e que tivessem estrutura de serviços de saúde em condições de ofertar campo de prática suficiente e de qualidade para os alunos (Brasil, 2013; Facchini et al., 2016).

Contudo, o que se observou foi a criação de vagas de graduação em medicina, majoritariamente em cursos privados. Não houve aumento e ocupação de vagas de residência médica. Também não se investiu em infraestrutura para a rede de saúde nem tampouco para aumentar o volume de atendimento assistencial da população. Além disso, há resistência coletiva dos cursos no que se refere a avaliações nacionais, como a avaliação nacional seriada dos estudantes de medicina, que foi aplicada apenas uma vez em 2016 e encontra-se suspensa. Desta forma, observa-se a predominância de interesses de grupos econômicos em detrimento aos nobres preceitos de criação da lei.

Diferente da maioria dos estudos até então realizados, que executam análises transversais sobre a oferta e distribuição de escolas de ensino médico no Brasil, os resultados deste estudo apresentam análise secular e longitudinal do crescimento do número de escolas médicas. Foi possível definir o padrão atual de distribuição dessas escolas no Brasil, suas principais características socioeconômicas, demográficas e das cidades nas quais estão inseridas.

Diversos fatores parecem influenciar a dinâmica de expansão de escolas de ensino médico no Brasil. Observa-se que a criação de novas escolas de ensino 
médico foi fortemente instigada pelas leis de mercado e gestão das políticas socioeconômicas, de saúde e de educação vigentes no país, o que tem tornado desigual a distribuição espaço-temporal dessas escolas.

Estudos mostram que é historicamente reconhecida a concentração desses médicos e vagas de ensino em grandes centros urbanos e em regiões mais desenvolvidas do país. A má distribuição com concentração urbana e déficits rurais não é característica somente do Brasil, pois quase todos os países sofrem esses desequilíbrios (Dal Poz, 2013; Sousa et al., 2015). Entretanto, o modelo de expansão do ensino médico observado no Brasil caracteriza-se por, simultaneamente, apresentar, por um lado, a concentração de escolas e vagas nas regiões e localidades mais ricas e urbanizadas e, por outro, a oferta questionável e pouco estruturada nas regiões e cidades com piores indicadores sociais e de saúde do país.

Esse duplo mecanismo foi implementado ao longo dos diferentes governos nacionais. Surgiu nos governos militares, que iniciaram a privatização e expansão do ensino para fora das capitais, mas mantiveram a concentração nas Regiões Sudeste e Sul do país. Esses processos agudizaram-se nos governos FHC e foram consolidados nos governos Lula e Dilma-Temer.

Essa privatização do ensino, entretanto, foi acompanhada por algumas políticas de financiamento, entre as quais se destacam o Programa de Crédito Educativo, o Fundo de Financiamento ao Estudante do Ensino Superior (Fies) e o ProUni.

O Programa de Crédito Educativo, criado em 1970 e institucionalizado em 1992, realizava empréstimo para reduzir as dificuldades de sustento dos alunos nas redes pública e privada. O Programa contou com financiamento de várias fontes, como o Ministério de Educação e Cultura (MEC), recursos próprios da Caixa Econômica Federal e do Banco do Brasil, além da participação de bancos privados. Contudo, considerando a inadimplência em relação à quitação dos empréstimos e outras questões políticas e econômicas, foi desativado no início da década de 2000.

O Fies, criado em 1999 pelo Ministério da Educação, é destinado a financiar até $100 \%$ da graduação no ensino superior de estudantes que não têm condições de arcar integralmente com os custos de sua formação. Por fim, o ProUni, instituído em setembro de 2004, visa a criar condições para o acesso de estudantes carentes ao ensino superior, por meio da oferta de bolsas de estudo, de diferentes modalidades. Uma delas é a bolsa de estudo integral concedida a brasileiros não portadores de diploma de curso superior, cuja renda per capita não exceda o valor de até um salário mínimo e meio. Já a bolsa de estudo parcial, equivalente a cinquenta por cento do valor do curso, é concedida a brasileiros não portadores de diploma de curso superior, cuja renda familiar per capita não exceda o valor de até três salários mínimos (Corbucci, 2004; Aprile e Barone, 2009). 
Desta forma, boa parte da privatização do ensino médico vem sendo financiada com dinheiro público (Chaves, Reis e Guimarães, 2018), gerando endividamento dos egressos com dificuldades de pagar a dívida e tendo o Governo Federal como fiador (Oliveira; Carnielli, 2010).

A consolidação do SUS com maior oferta de postos de trabalho médico e maior demanda de necessidades de saúde também tem influências sobre esse crescimento. Por outro lado, pressões mercadológicas e econômico-financeiras tornam a formação médica orientada pelas leis e interesses de mercado, de demanda e procura, gerando-se crescimento substancial na oferta de escolas e vagas privadas de medicina voltadas a atender interesses de grupos socioeconômicos mais favorecidos. Desta forma, esse crescimento não beneficia a população de forma homogênea, nem atende à resolução das necessidades e vulnerabilidades ainda evidentes na população do país (Scheffer et al., 2018a; Campos e Pereira Junior, 2016).

No governo Dilma-Temer, a expansão do ensino médico pelo PMM capilarizou a educação médica, levando-a a ocorrer em áreas remotas, rurais, nos subúrbios dos grandes centros ou nas áreas urbanas de regiões e cidades socioeconomicamente mais desfavorecidas do país (Carvalho, Marques e Silva, 2016). No entanto, apesar dessa expansão de vagas de graduação em medicina, as desigualdades na distribuição de escolas de ensino médico permanecem evidentes entre as unidades da federação, capitais, interiores das regiões e nos agrupamentos de municípios por estratos populacionais (Scheffer, 2018b; Campos e Pereira Junior, 2016). Um exemplo dessa concentração está nos achados deste estudo: Capitais da Região Sudeste abrigam mais vagas (4.537) do que regiões inteiras, como Norte (2.469) e Centro-Oeste (2.663); Juntas $(17,5 \%)$, essas duas regiões têm menos escolas de medicina que todo o Estado de São Paulo (18,6\%).

Essa desigualdade na oferta de escolas tem influências importantes sobre a distribuição e fixação de médicos entre regiões e intrarregiões. Nos últimos anos, houve crescimento exponencial do número de médicos no país. Dados de demografia médica indicam que, em 1970, eram 58.994 registros enquanto, em 2017, foram contabilizados 451.777. Esses dados revelam um aumento de $665 \%$, contra um crescimento de $119 \%$ da população brasileira no mesmo período. Ou seja, o total de médicos nesses anos aumentou em maior velocidade do que o crescimento populacional. Este mesmo estudo mostrou que o Brasil possuía uma razão nacional de 2,18 médicos/1.000 habitantes em janeiro de 2018 (Scheffer, 2018b). Todavia, nas Regiões Norte e Nordeste, essa razão ficava abaixo da razão nacional (1,16 e 1,41, respectivamente). Nessas duas regiões, estão as unidades da federação com menor número de médicos em relação à população. Por sua vez, a Região Sudeste conta com o maior número de médicos por 1.000 habitantes $(2,81)$, acima da Região Sul $(2,31)$ e da Centro-Oeste $(2,36)$ (Scheffer, 2018b). 
Logo, as características de um país extenso e bastante heterogêneo como o Brasil tornam evidentes a necessidade de médicos e de outros profissionais de saúde para suprirem as demandas de atendimento à população nos diversos serviços de saúde (Seixas, Correia e Moraes, 2014; Campos e Pereira Junior, 2016).

Apesar disso, não se pode acreditar que a simples criação de cursos de medicina em regiões do interior e, principalmente, naquelas mais remotas, irá atender às necessidades e especificidades da atenção à saúde nessas regiões. Além destas expectativas não serem atendidas nestas localizações, invariavelmente pobres em recursos humanos, financeiros e tecnológicos, também pode ser experiência altamente frustrante para estudantes, professores e população local que ansiavam por uma melhor qualidade de formação e assistência.

Um reflexo disto é a taxa de evasão de estudantes. De acordo com Scheffer et al. (2018a), mais da metade dos alunos de medicina que se formaram entre 1980 e 2014 mora em estado diferente do que aquele no qual se formou. Observou-se, ainda, que os alunos de faculdades particulares migram mais que os alunos das universidades públicas. Para os autores, a simples proposta de aumento de vagas nas regiões mais necessitadas não garante diretamente a permanência dos médicos no local.

Nesse contexto, o investimento em propostas de escolas médicas com currículos não apenas orientados, mas também baseados na comunidade, e com ênfase na atenção primária à saúde, deve ser fortemente incentivado, não apenas no discurso, mas também na verdadeira transformação das realidades locais. Prática semelhante foi adotada na Austrália, que, como o Brasil, é um país continental, o qual sofre com a escassez de médicos em áreas remotas (Larkins e Gupta, 2013). O governo australiano promoveu seleção de estudantes de áreas rurais e o desenvolvimento de estágios e internatos nessas mesmas regiões, além de estimular que os estudantes frequentassem campi mais próximos de suas cidades natais (Clark et al., 2013).

Para que ocorra esta reorganização do currículo, com práticas voltadas à atenção básica, é necessário que haja o alinhamento de medidas e apoios conjuntos e colaborativos entre municípios, estado e as instituições de ensino superior, muitas vezes superando questões político-partidárias. Se isto não acontecer, os cursos médicos dessas localidades terão muitas dificuldades em se desenvolver.

Cabe destacar a importância dos processos de avaliação de desempenho dos estudantes dos cursos médicos frente a todas as mudanças da formação e da aquisição de competências necessárias para atender as necessidades dos usuários e do SUS. Isso é possível com a manutenção do Exame Nacional dos Estudantes como parte do Sistema Nacional de Avaliação da Educação Superior e o aprimoramento da Avaliação Nacional Seriada dos Estudantes de Medicina no $2^{\circ}, 4^{\circ}$ e $6^{\circ}$ anos (neste último ano, necessariamente, com avaliação também prática). Desta forma, responsabilizam-se, conjuntamente, os estudantes e seus cursos de graduação pela adequação da formação médica a cada um dos 
momentos pré-definidos, diferentemente de uma avaliação terminal como no 'Exame de Ordem', que não é recomendada. Isto somente irá estimular a criação de 'cursinhos' preparatórios, que são voltados apenas para a realização da prova e não para a vida prática e humanização do médico.

É necessário que as entidades atuantes no controle da educação superior e, principalmente médica, defendam a necessidade de acompanhamento e avaliação de todo o processo de formação dos médicos e não venham a se eximir de seus papéis institucionais. Exemplos dessas entidades são o Conselho Nacional de Educação, Conselho Nacional de Saúde, Associação Nacional dos Dirigentes das Instituições Federais de Ensino Superior, Instituto Nacional de Estudos e Pesquisas Educacionais, Conselho Federal de Medicina, Associação Brasileira de Educação Médica e demais entidades que não tiveram uma participação efetiva nas decisões sobre o processo de abertura das escolas médicas. Do mesmo modo, deve ser feita a defesa da prova do Revalida nos moldes definidos pela Portaria Interministerial n. 278, de 17 de março de 2011, de forma única para todo o país (Ministério da Educação e Ministério da Saúde, 2011).

Convém apresentar algumas limitações deste estudo. Optou-se por não considerar as escolas que foram extintas até 2017 por entender que elas não têm mais papel no atual padrão de distribuição e oferta de vagas de medicina e de formação médica no Brasil. Outra limitação seria que o número de alunos matriculados pode não ser o mesmo de vagas autorizadas pelo MEC, indicando que a evasão universitária e a repetência de anos de estudos de medicina podem ter peso no número de estudantes de medicina e de médicos egressos de escolas de ensino médico do país.

Apesar disso, os resultados apresentam o padrão de desenvolvimento e a dinâmica de evolução e distribuição das escolas de medicina no Brasil segundo seus governos desde 1808 até 2018. Indicam forte influência de fatores macroeconômicos e estruturais no padrão de oferta desse tipo de ensino ao longo de pouco mais de dois séculos de história do ensino médico no país, principalmente no que se refere à fase recente da interação das políticas de educação e saúde no Brasil.

Os resultados apresentados poderão servir de base para estudos mais aprofundados e segmentados, envolvendo os múltiplos aspectos que permeiam a formação médica, como a abertura de novos cursos, a regionalização, a caracterização das políticas sociais de saúde e educação e desempenho relativo ao desenvolvimento social e econômico do país.

\section{Conclusões}

A expansão das escolas médicas no Brasil, independentemente do partido político ou do dirigente ocupando a direção executiva do país, teve as 
mesmas linhas gerais de atuação: incentivo à privatização do ensino médico e expansão da distribuição entre as regiões do país.

Acredita-se ser bem-vinda e necessária a interiorização dos cursos públicos e privados e a distribuição mais equitativa entre as regiões e cidades de diferentes portes populacionais do Brasil. Dessa forma, é possível reduzir as diferenças locorregionais na proporção de escolas médicas e na taxa de vagas de graduação por habitantes. Essa realidade, porém, deve estar associada à melhoria da qualidade da assistência aos usuários do SUS. É importante considerar que esse processo não ocorrerá sem adequado e rigoroso acompanhamento e avaliação feita por profissionais capacitados tecnicamente, isentos de conflitos de interesse, com experiência real em educação e assistência médica.

Entre os cursos implantados, há diferentes realidades de infraestrutura, corpo docente e projetos pedagógicos. Logo, é necessário o alinhamento de ações e apoio colaborativo entre municípios, estados e instituições políticas, sociais e de saúde no intuito de auxiliar a efetiva consolidação dos cursos e sua contribuição na resolução das necessidades e demandas das comunidades em que estão inseridos.

Diante da expansão de escolas médicas demonstrada, conclui-se este estudo com alguns questionamentos relevantes para futuras investigações: Quais os mecanismos de controle do investimento financeiro realizado nos cursos públicos de interiorização, encaminhados para os órgãos centrais das universidades? Existe infraestrutura de serviços e de rede de saúde, bem como cenários de prática adequados para a formação médica? Existem políticas suficientes para a formação e desenvolvimento de professores, principalmente os de interiorização, longe dos aparelhos formadores dos grandes centros? Quais as políticas de incentivos, motivação e capacitações técnica e pedagógica dos preceptores não docentes que acompanharão os graduandos nos cenários de prática? Nos cursos privados com a oportunidade de financiamento público (FIES e Pro Uni), como está o rigor do processo de seleção e acompanhamento, bem como o grau de comprometimento financeiro e inadimplência dos egressos? Como está a implementação dos mecanismos de fixação de médicos em cursos de áreas com menor relação médico por habitante tais como os argumentos de inclusão regional (bonificação no Exame Nacional do Ensino Médio)? Como está a abertura de vagas de residência médica para suprir o aumento de formandos e a regulação e acompanhamento da ocupação dessas vagas e da qualidade dos programas oferecidos? Como está o processo de implementação do Contrato Organizativo de Ação Pública Ensino-Serviço nos municípios e regiões de saúde dos cursos de medicina e das demais profissões da saúde, bem como a pactuação do plano de contrapartida das instituições públicas e privadas? Como mensurar e acompanhar a participação assistencial dos graduandos e médicos residentes na rede de saúde dos municípios e 
regiões onde foram implantados? Como está o processo de acompanhamento e avaliação dos projetos pedagógicos desses novos cursos médicos? Quem são os avaliadores, como foram selecionados e capacitados? Como lidar com as não conformidades? Quais as políticas de educação interprofissional e de empoderamento da população estão sendo realizadas? Quais as políticas que focalizam e garantem os processos de educação permanente dos profissionais médicos já formados?

Portanto, é necessário saber se o processo de expansão que vem ocorrendo está tendo a devida atenção e acompanhamento dos órgãos e universidades públicas e de organizações da sociedade civil, com vistas aos tipos de resultados de médio a longo prazos que ocorrerão na formação médica e de assistência à saúde.

\section{Colaboradores}

Bruno Luciano Carneiro Alves de Oliveira, Sara Fiterman Lima e Gerson Alves Pereira Júnior participaram igualmente de todas as fases de elaboração do manuscrito e aprovaram a versão final do artigo. Marina Uchoa Lopes Pereira participou da redação, revisão crítica e aprovação da versão final do artigo.

\section{Financiamento}

Os autores agradecem à Fundação de Amparo à Pesquisa e ao Desenvolvimento Científico e Tecnológico do Maranhão (Fapema) pelo auxílio recebido por meio do Edital de Apoio à Publicação de Artigos Científicos.

\section{EVOLUCIÓN, DISTRIBUCIÓN Y EXPANSIÓN DE LAS CARRERAS DE MEDICINA EN BRASIL (1808-2018)}

Resumen El estudio identificó el patrón de evolución, distribución y expansión de las carreras de Medicina en Brasil y describió los procesos gubernamentales relacionados al aumento de la oferta de vacantes. Se trata de un estudio descriptivo, con base en datos disponibles en el sistema del Ministerio de Educación sobre escuelas de medicina. Con la información sobre las carreras, desde las primeras implantadas, se establecen seis períodos de gobierno para análisis: desde 1808 hasta 1963 (monarquía y gobiernos republicanos iniciales), desde 1964 hasta 1988 (gobiernos militares - José Sarney), desde 1989 hasta 1994 (Fernando Collor - Itamar Franco), desde 1995 hasta 2002 (Fernando Henrique Cardoso), desde 2003 hasta 2010 (Lula) y desde 2011 hasta 2018 (Dilma Rousseff - Michel Temer). Se observó una importante aumento de las escuelas a partir de los gobiernos militares, con un pico en el 2014 (Dilma Rousseff), frente a la implementación 
del Programa Más Médicos. A lo largo de los períodos analizados la educación médica se ha ido privatizando progresivamente y se trasladó parcialmente hacia las Regiones Norte, Nordeste y Centro-Oeste, y a ciudades de tamaño medio y pequeño en el interior de los estados. Los resultados indican que la combinación de la gestión gubernamental de las políticas de salud y educación y de desarrollo socioeconómico influyeron en la expansión de las carreras de medicina y las marcadas diferencias intra e interregionales.

Palabras clave educación médica; políticas de salud; distribución de médicos; expansión; interiorización de escuelas de medicina.

\section{Referências}

ABDALLA, Ively G. et al. Projeto pedagógico e as mudanças na educação médica. Revista Brasileira de Educação Médica, Brasília, v. 33, p. 44-52, 2009.

AMÂNCIO FILHO, Antenor; VIEIRA, Ana L. S.; GARCIA, Ana C. P. Oferta das graduações em Medicina e em Enfermagem no Brasil. Revista Brasileira de Educação Médica, Brasília, v. 30, p. 66-75, 2006.

AMARAL Jose L. G. O exame terminal salvaguarda a Medicina. Revista da Associação Paulista de Medicina, São Paulo, v. 682, p.1617, out. 2016.

APRILE, Maria R.; BARONE, Rosa E. M. Educação superior: políticas públicas para inclusão social. Revista@mbienteeducação, São Paulo, v. 2, n. 1, p. 39-55, 2018.

BRASIL. Constituição da República Federativa do Brasil, de 1988. Diário Oficial da República Federativa do Brasil, Poder Executivo, Brasília, DF, 05 de outubro. 1988. Seção I, p. 1.

BRASIL. Portaria n. 86, de 22 de março de 2018. Dispõe sobre Propostas de expansão de vagas do ensino médico nas Instituições Federais do Ensino Superior elaboradas pelo Grupo de Trabalho instituído pela Diário Oficial da União. 27 Mar 2012.

BRASIL. Lei $\mathrm{n}^{\circ}$ 8.745, de 9 de dezembro de 1993. Instituição do Programa Mais Médicos. Diário Oficial [da] República Federativa do Brasil, Poder Executivo, Brasília, DF, 10 nov. 2013.
BRASIL. Resolução n ${ }^{\circ}$ 3, de 20 de junho de 2014. Institui Diretrizes Curriculares Nacionais do Curso de Graduação em Medicina e dá outras providências. Diário Oficial [da] República Federativa do Brasil, Poder Executivo, Brasília, DF, 23 jun. 2014.

BRASIL. Ministério da Educação. Portal da Educação. Instituições de Educação Superior e Cursos Cadastrados. (e-MEC): 2018. Disponível em: <http://emec.mec.gov.br/>. Acesso em: 10 ago. 2018.

CAMPOS, Gastão W. S.; PEREIRA JUNIOR, Nilton. A Atenção Primária e o Programa Mais Médicos do Sistema Único de Saúde: conquistas e limites. Ciência \& Saúde Coletiva, Rio de Janeiro, v. 21, n. 9, p. 2.655-2.663, set. 2016.

CARVALHO, Viviane K. S.; MARQUES, Carla P.; SILVA, Everton N. A contribuição do Programa Mais Médicos: análise a partir das recomendações da OMS para provimento de médicos. Ciência \& Saúde Coletiva, Rio de Janeiro, v. 21, n. 9, p. 2.773-2.784, set. 2016 .

CHAVES, Vera L. J.; REIS, Luiz F.; GUIMARÃES, André R. Dívida pública e financiamento da educação superior no Brasil. Acta Scientiarum Education, Maringá Paraná, v. 40, p. 5, 2018.

CLARK, Tyler R. Medical graduates becoming rural doctors: rural background versus extended rural placement. Medical Journal of Australia, Sydney, Austrália, v. 199, n. 11, 779-782, 2013.

DAL POZ, Mario R. A crise da força de trabalho em saúde. Cadernos de Saúde Pública, Rio de Janeiro, v. 29, n. 10, p. 1.924-1.926, 2013. 
FACCHINI, Luiz A. O Programa Mais Médicos: análises e perspectivas. Ciência \& Saúde Coletiva, Rio de Janeiro, v. 21, n. 9, p. 2.652, set. 2016 .

HADDAD, Ana E. et al. Formação de profissionais de saúde no Brasil: uma análise no período de 1991 a 2008. Revista de Saúde Pública, São Paulo, v. 44, n. 3, p. 383-393, 2010.

LAMPERT, Jadete B. Dois séculos de escolas médicas no Brasil e a avaliação do ensino médico no panorama atual e perspectivas. Gazeta Médica da Bahia, Bahia, v. 78, n. 1, 2008.

LARKINS, Sarah; Gupta, Tarun S. Recruitment and retention of general practitioners in rural Canada and Australia: a review of the literature. Canadian Journal of Rural Medicine, Toronto, v. 18, n. 1, 2013.

MELLO, Guilherme A.; DEMARZO, Marcelo M. P. Novas escolas médicas e a regionalização. Região e Redes, maio 2015. Disponível em: <http://www.resbr.net.br/wp-content/ uploads/2015/05/Novos_Caminhos_03_Final. pdf $>$. Acesso em: 21 out. 2017.

OLIVEIRA, Zenaide R. B. B.; CARNIELLI, Beatrice L. Fundo de Financiamento ao Estudante do Ensino Superior (FIES): visão dos estudantes. Jornal de Politicas Educacionais, Paraná, v. 4, n. 7, 2010.

OLIVEIRA, Felipe P. et al. Mais Médicos: um programa brasileiro em uma perspectiva internacional. Interface - Comunicação, Saúde, Educação, Botucatu, v. 19, n. 54, p. 623-634, set. 2015.
OLIVEIRA, João P. A.; SANCHEZ, Mauro N.; SANTOS, Leonor M. P. O programa mais médicos: provimento de médicos em municípios brasileiros prioritários entre 2013 e 2014. Ciência \& Saúde Coletiva, Rio de Janeiro, v. 21, n. 9 , p. 2.719-2.727, set. 2016.

SANTOS, Leonor M. P.; COSTA, Ana M.; GIRARDI, Sábado N. Programa Mais Médicos: uma ação efetiva para reduzir iniquidades em saúde. Ciência \& Saúde Coletiva, Rio de Janeiro, v. 20, n. 11, p. 3.547-3.552, nov. 2015.

SCHEFFER, Mario C. et al. Internal migration of physicians who graduated in Brazil between 1980 and 2014. Human resources for health, Sidney, v. 16, n. 21, maio 2018a.

SCHEFFER, Mario C. et al. Demografia médica no Brasil 2018. São Paulo: FMUSP, CFM, CREMESP, 2018b. 286 p.

SEIXAS, Paulo H. D.; CORRÊA Aniara N.; MORAES, José C. Migramed: migração médica no Brasil: tendências e motivações. São Paulo: Observatório de Recursos Humanos em Saúde de São Paulo, 2014.

SILVA, Lucas A.; MUHL, Camila; MOLIANI, Maria M. Ensino médico e humanização: análise a partir dos currículos de cursos de medicina. Psicologia Argumento, Curitiba, PR, v. 33, n. 80, 2015.

SOUSA, Maria F. et al. Por que mais médicos no Brasil?: da política à formação. Tempus Actas de Saúde Coletiva, Brasília, v. 9, n. 4, p. 159-174, 2015.

\section{ERRATA}

No artigo EVOLUÇÃO, DISTRIBUIÇÃO E EXPANSÃO DOS CURSOS DE MEDICINA NO BRASIL (1808-2018), com número de DOI: 10.1590/1981-7746-sol00183, publicado no periódico Trabalho, Educação e Saúde, v. 17, n. 1, identificador eletrônico 17(1):e0018317, página 18, foi incluído o seguinte título em espanhol: 